\title{
O PROGRAMA BOLSA FAMÍLIA NO MUNICÍPIO DE ELÓI DE SOUZA/RN: a condicionalidade relativa à frequência escolar contribui para a permanência dos estudantes?
}

\author{
Jane Soares Saturnino de Lima38 \\ Andreia da Silva Quintanilha Sousa ${ }^{39}$
}

\begin{abstract}
RESUMO
Este artigo buscou refletir sobre o Programa Bolsa Família - PBF e as contribuições de suas condicionalidades, abordando a questão da frequência escolar na perspectiva de favorecer a permanência dos estudantes usuários do PBF. Tendo como realidade empírica a Escola Municipal Euclides Lins, zona rural, em Senador Elói de Souza/RN, cuja amostra é composta pelos estudantes matriculados no ensino fundamental $\|-6^{\circ}$ ao $9^{a}$ - no período de 2014 a 2015. Os resultados encontrados revelam que, no período estudado, o total de usuários do PBF matriculados era de $83 \%$ em 2014 e 77,5\% em 2015, com uma média de frequência acima de $95 \%$ nos dois anos, apresentando uma taxa média de evasão de $2 \%$. Assim, no tocante às condicionalidades de frequência escolar, a pesquisa revelou que o programa tem contribuído para elevar as taxas de matrículas, uma vez que a escola apresentou uma população estudantil composta por uma maioria de usuários do PBF. Todavia, cabe salientar a necessidade de integração com outros programas que apontem para a promoção de direitos e que construam as condições para sua emancipação.
\end{abstract}

Palavras-chave: Bolsa Família. Educação. Frequência Escolar e Evasão.

\section{THE BOLSA FAMÍLIA PROGRAM IN THE MUNICIPALITY OF ELÓI DE SOUZA/RN: \\ does conditionality on school attendance contribute to increase in years of schooling?}

\begin{abstract}
This article sought to reflect on the Bolsa Familia Program - PBF and the contributions of its conditionality, addressing the issue of school attendance with a view to favoring the permanence of the students who use the PBF. The study was conducted at a rural municipal school in Senador Elói de Souza / RN, and the students enrolled

38 Graduada em Serviço Social e Especialização em Educação, pobreza e desigualdade social pela Universidade Federal do Rio Grande do Norte. E-mail:janedjavan@yahoo.com.br

39 Professora Associada da Universidade Federal de Rondônia. Lotação provisória no Departamento de Fundamentos e política da Educação da Universidade Federal do Rio Grande do Norte.E-mail: andreia_quintanilha_sousa@homail.com
\end{abstract}


in fundamental education II (lower secondary school) - from the 6th to the 9th grade - in the period from 2014 to 2015 constituted the sample of the targeted population of students. The results show that, in the period studied, the total number of PBF users enrolled was 83 percent in 2014 and 77.5 percent in 2015 . In both years, the attendance rate was above 95 percent and the dropout rate was 2 percent. Thus, with regard to school attendance conditionality, the survey revealed that the program has contributed to raising enrollment rates, since the school had a student population composed of a majority of PBF users. However, it is important to stress the need for integration of schools with other programs that aim at the promotion of rights and that build the conditions for the emancipation of the students.

Keywords: Bolsa Família. Education. School Attendance and Dropout.

\section{O PROGRAMA DE TRANSFERÊNCIA CONDICIONADA DE RENDA BOLSA FAMÍLIA E SUAS CONDICIONALIDADES}

O Bolsa Família é um programa de transferência condicionada de renda, instituído pelo Presidente Luiz Inácio Lula da Silva (2003 a 2010), por meio da lei $n^{\circ}$ 10.836, de 09 de janeiro de 2004, cujo público-alvo são as famílias $^{40}$ consideradas extremamente pobres ${ }^{41}$ (com renda mensal por pessoa de 0 até 85,00 - oitenta e cinco reais) ou pobres (com renda mensal por pessoa de $R \$ 85,01$ - oitenta e cinco reais e um centavo até $R \$ 170,00$ cento e setenta reais) (MDSA, 2016). Todavia, a criação desse programa não foi uma experiência inédita no Brasil.

Segundo pesquisa realizada por Weisshenimer (2006), a primeira experiência de programa de transferência de renda no Brasil data da década de 1990. Tendo como projeto de lei pioneiro o "Programa Garantia de Renda Mínima42 do senador Eduardo Suplicy (PT-SP) em 1991"

\footnotetext{
40 Para o programa PBF a definição de família que norteiam as ações é expressa da seguinte forma: "família, a unidade nuclear, eventualmente ampliada por outros indivíduos que com ela possuam laços de parentesco ou de afinidade, que forme um grupo doméstico, vivendo sob o mesmo teto e que se mantém pela contribuição de seus membros" (BRASIL, 2004).

${ }^{41}$ Para obter mais informações sobre o Programa Bolsa Família, consultar o site oficial do Governo Federal. Disponível em: <http://mdspravoce.mds.gov.br/bolsa-familia/quem-podereceber/>. Acesso em: 1 out. 2016.

42 O programa Garantia de Renda Mínima ou Imposto de Renda Negativo, como ficou conhecido, incidiria da mesma maneira que as pessoas que ganham além de um certo patamar pagam uma proporção de seus rendimentos ao governo, na forma do Imposto de Renda, aquelas que ganham menos passariam a ter o direito de receber uma proporção da
}

Revista Exitus, Santarém/PA, Vol. 7, № 1, p. 131-159, Jan/Abr 2017. 
(WEISSHENIMER, 2006, p. 26). Embora tenha sido aprovado, não foi de fato implementado.

Posteriormente, em 1995, o Governado do Distrito Federal Cristovão Buarque implementou o Programa Bolsa Educação43. Nesse mesmo ano, o "prefeito de Campinas/SP José Roberto Magalhaes Teixeira iniciou o Programa Renda Familiar Mínima ${ }^{44}$ e em Ribeirão Preto/SP, com Antônio Palocci" (WEISSHENIMER, 2006, p. 27).

Em 2001, o presidente Fernando Henrique Cardoso (1995 a 2002) lançou algumas políticas de enfrentamento à pobreza denominado "Programa de Erradicação do Trabalho Infantil - PETl; Agente Jovem; Sentinela; Bolsa Escola; Bolsa Alimentação e Auxílio Gás" (WEISSHENIMER, 2006, p. 29). Sendo algumas dessas políticas sequenciadas como pode ser observado no Decreto $n^{\circ}$ 10.836, de 09 de janeiro de 2004, que instituiu 0 Programa Bolsa Família:

O Programa de que trata o caput tem por finalidade a unificação dos procedimentos de gestão e execução das ações de transferência de renda do Governo Federal, especialmente as do Programa Nacional de Renda Mínima vinculado à Educação - Bolsa Escola, instituído pela Lei $n^{\circ} 10.219$, de 11 de abril de 2001, do Programa Nacional de Acesso à Alimentação - PNAA, criado pela Lei n o 10.689, de 13 de junho de 2003, do Programa Nacional de Renda Mínima vinculada à Saúde - Bolsa Alimentação, instituído pela Medida Provisória n o 2.206-1, de 6 de setembro de 2001, do Programa Auxílio-Gás, instituído pelo Decreto $n^{\circ}$ 4.102, de 24 de janeiro de 2002, e do Cadastramento Único do Governo Federal, instituído pelo Decreto n 3.877, de 24 de julho de 2001 (BRASIL, 2004).

A diretriz adotada possibilitou não só a unificação dos programas já existentes, como também permitiu dar mais fluidez às ações de combate à

diferença, $50 \%$, entre aquele patamar e o seu nível de rendimento. Daí por que o nome Imposto de Renda Negativo (SUPLICY, 1991).

43 O Programa Bolsa Escola nasceu vinculado ao Ministério da Educação, com objetivo de contribuir para permanência na escola pública de crianças de 7 a 14 anos. Atendeu 10 cidades do DF, beneficiando 25.568 famílias, ou 50.726 alunos.

44 O Programa de Renda Mínima destinava um complemento em dinheiro à renda de famílias consideradas miseráveis (abaixo da linha da pobreza). Para receber o recurso, a família inscrita no programa deveria residir em Campinas há pelo menos dois anos, manter os filhos na escola e com bons resultados nos estudos. 
pobreza e extrema pobreza vivenciadas por aproximadamente 87 milhões de brasileiros naquele período, conforme destaca Weisshenimer (2006).

Em 2011, a presidenta Dilma Rousseff (2011 a 2016) lançou o Plano Brasil Sem Miséria45, tendo como objetivo "aprofundar ainda mais as conquistas obtidas no governo Lula, que permitiram crescer distribuindo renda, reduzindo desigualdades e promovendo inclusão social [...] buscando a superação da extrema pobreza" (MDS, 2013). Nesse plano serão efetuadas "cerca de 100 ações, distribuídas em três grandes eixos de atuação: garantia de renda, acesso a serviços e inclusão produtiva" (MDS, 2013, p. 10), tendo como público-alvo as famílias beneficiadas pelo Programa Bolsa Família.

Para garantir a viabilidade técnica dessa política, foi necessário garantir os meios para construir um sistema que proporcionasse a implementação e monitoramento das ações de combate à fome e à pobreza. Para tanto, foram criados alguns mecanismos que facilitaram a implementação e monitoramento do programa e seus efeitos na qualidade de vida da população brasileira.

Entre esses mecanismos, os mais preponderantes foram a constituição do Ministério do Desenvolvimento Social e Combate a Fome - MDS, atualmente $^{46}$ unificado com $\bigcirc$ Ministério do Desenvolvimento Agrário, passando a ser denominado MDSA 47 , fortalecimento do Cadastro Único, Índice de Gestão Descentralizada - IGD48; Sistema Único de Assistência

45 Para maiores informações sobre o Plano Brasil sem Miséria, consultar a cartilha. Disponível em: $\quad<$ http://aplicacoes.mds.gov.br/sagi/Rlv3/dadosSv/cartilha_msm/CartilhaBSM.pdf>. Acesso em: 1 out. 2016.

${ }^{46}$ No governo do presidente Michael Temer, ocorreu uma série de mudanças entre as quais a unificação de dois ministérios com políticas extremamente importantes para promoção da justiça social, porém contendo diferenças significativas que podem ser comprometidas por essa determinação, sobretudo em relação ao orçamento destinado a ambas.

47 Para maiores informações sobre os programas e planos de combate à pobreza, consultar a página http://mds.gov.br/.

48 Com base no IGD que são calculados os repasses mensais que o ministério faz aos municípios para ajudar na gestão do Cadastro e do Bolsa Família. 
Social - SUAS49 (2005) formam o tecido que compõem as ações de combate a pobreza e as desigualdades sociais nesse país.

Considerando que o objetivo do programa é combater a pobreza e contribuir para superação da desigualdade social, as condicionalidades foram delimitadas contemplando as dimensões que compõe a qualidade de vida das populações em situação de pobreza ou extrema pobreza, a saber: educação, saúde, alimentação e renda. Conforme expresso no artigo 3o lei n 10.836, 2004;

A concessão dos benefícios dependerá do cumprimento, no que couber, de condicionalidades relativas ao exame pré-natal, ao acompanhamento nutricional, ao acompanhamento de saúde, à frequência escolar de $85 \%$ (oitenta e cinco por cento) em estabelecimento de ensino regular, sem prejuízo de outras previstas em regulamento (BRASIL, 2004).

Diante dessas condicionalidades o PBF também determina as penalidades que incidirão nas famílias que não cumprir com seus compromissos. Ou seja, diante do não cumprimento das condicionalidades, a família poderá sofrer as seguintes sansões: Advertência; suspensão; bloqueio e esgotadas todas as formas de chamar atenção da família ocorre o cancelamento do benefício.

Assim, o sistema de condicionalidades exige uma equipe que acompanhe e desenvolva um trabalho social com as famílias que se encontram nessa situação. Para isso, o PBF conta com o Cadastro Único, um banco de dados do governo federal que possui uma estrutura em cada município para favorecer o cadastramento e atualização das famílias beneficiárias. É também responsável por fornecer a lista com o nome das famílias que apresentam descumprimento das condicionalidades para acompanhamento junto aos Centros de Referência de Assistência Social CRAS.

49 O Sistema Único de Assistência Social - SUAS, descentralizado e participativo, tem por função a gestão do conteúdo específico da Assistência Social no campo da proteção social brasileira.

Revista Exitus, Santarém/PA, Vol. 7, № 1, p. 131-159, Jan/Abr 2017. 
O CRAS é um importante equipamento de fortalecimento da cidadania e proteção social que compõe uma das dimensões da política de assistência social, cuja função é proteção social das famílias em situação de vulnerabilidade e risco social. Inclusive, a equipe técnica do CRAS é responsável por desenvolver um trabalho social com as famílias em situação de descumprimento das condicionalidades do PBF na perspectiva de viabilizar direito e não meramente a punição pelo descumprimento de uma condicionalidade.

Em outras palavras, o acompanhamento das famílias em descumprimento das condicionalidades favorece a identificação das fragilidades e dificuldades apresentadas por elas no acesso aos serviços de educação, saúde e alimentação. A partir dessas informações, é possível cobrar dos gestores melhorias nesses serviços e evitar as sanções previstas pelo PBF, favorecendo a população de um modo geral.

Quanto aos valores dos benefícios oriundos do PBF, esses são divididos em duas categorias denominados de benefício básico e benefício variável. O beneficio básico é um valor fixo que pode ser acrescido pelas variáveis, caso as famílias beneficiadas apresentem em sua composição crianças e/ou adolescentes 50 , gestantes e/ou nutrizes.

Atualmente o valor destinado ao beneficio básico é de $\operatorname{R} \$ 89,00$ (oitenta e nove reais) e o variável jovem destinado àqueles da faixa etária entre 16 a 17 anos é de $R \$ 49,00$ (quarenta e nove reais). A variável para gestante, nutrizes e crianças e adolescente na faixa etária de 0 a 15 anos é de $R \$ 39.00$ (trinta e nove reais). O beneficio é creditado na conta bancaria do responsável pela unidade familiar, onde poderão ser beneficiados até cinco filhos menores de 18 anos, tendo com fonte pagadora a Caixa Econômica Federal.

Diante do breve exposto é fundamental observar que o PBF foi sendo ampliado e fortalecido por outros programas correlatos e legislações sociais

50 Art. $2^{\circ}$ Considera-se criança, para os efeitos desta Lei, a pessoa até doze anos de idade incompletos, e adolescentes aquela entre doze e dezoito anos de idade.

Revista Exitus, Santarém/PA, Vol. 7, № 1, p. 131-159, Jan/Abr 2017. 
que formaram uma rede de atenção aos usuários do programa como será demostrado no quadro a seguir:

Quadro 1 - Síntese do Programa Bolsa Família e as legislações correlatas.

\begin{tabular}{|c|c|c|c|}
\hline Período & $\begin{array}{l}\text { Famílias } \\
\text { Atendidas }\end{array}$ & $\begin{array}{l}\text { Programas Transversais de fomento à } \\
\text { cidadania, segurança alimentar, } \\
\text { saúde, emprego e renda e educação. }\end{array}$ & Legislações \\
\hline 2003 & 3.600 .000 & $\begin{array}{l}\text { Programa Luz para todos, Programa } \\
\text { Brasil Alfabetizado e Programa de } \\
\text { Aquisição de Alimentos - PAA. }\end{array}$ & $\begin{array}{l}\text { Regulamentação da Lei } \\
\text { Orgânica da Assistência } \\
\text { Social. }\end{array}$ \\
\hline 2004 & 6.600 .000 & $\begin{array}{l}\text { Programa Farmácia para todos, } \\
\text { Programa Brasil Sorridente (saúde } \\
\text { bucal), Programa Nacional de } \\
\text { Aquisição de Documento da } \\
\text { Trabalhadora Rural - PNDTR. }\end{array}$ & $\begin{array}{l}\text { Criação do SUAS - Sistema } \\
\text { Único de Assistência Social, } \\
\text { Criação do Ministério do } \\
\text { Desenvolvimento Social e } \\
\text { Combate à Fome - MDS. }\end{array}$ \\
\hline 2005 & 8.700 .000 & $\begin{array}{l}\text { Programa Nacional de Inclusão de } \\
\text { Jovens - Pro Jovem, Programa de } \\
\text { Erradicação do Trabalho Infantil - PETI, } \\
\text { Programa Universidade para Todos - } \\
\text { PROUNI. }\end{array}$ & \\
\hline 2006 & 11.000 .000 & $\begin{array}{l}\text { Ampliação do Programa Farmácia } \\
\text { Popular incluindo a rede privada. }\end{array}$ & $\begin{array}{l}\text { Criação do Índice de } \\
\text { Gestão Descentralizada - } \\
\text { IGD. }\end{array}$ \\
\hline 2007 & 11.000 .000 & $\begin{array}{l}\text { Programa Olhar Brasil (oftalmologistas), } \\
\text { Programa Mais Educação, Programa } \\
\text { de Reestruturação e Expansão das } \\
\text { Universidades Federais - REUNI, } \\
\text { Programa Caminho da Escola } \\
\text { (Transporte). }\end{array}$ & $\begin{array}{l}\text { Instituição do fundo de } \\
\text { Desenvolvimento da } \\
\text { Educação Básica - FUNDEB, } \\
\text { Criação do Índice de } \\
\text { Desenvolvimento da } \\
\text { Educação Básica - IDEB. }\end{array}$ \\
\hline 2008 & 10.900 .000 & $\begin{array}{l}\text { Programa Mulheres Mil no Norte e } \\
\text { Nordeste, Projeto de Inclusão Bancária } \\
\text { dos beneficiários do Programa Bolsa } \\
\text { Família. }\end{array}$ & \\
\hline 2009 & 12.300 .000 & $\begin{array}{l}\text { Programa Minha Casa Minha Vida, } \\
\text { Programa Microempreendedor } \\
\text { Individual - MEl. }\end{array}$ & \\
\hline 2010 & 12.800 .000 & $\begin{array}{l}\text { Utilização do Cadastro Único para } \\
\text { seleção dos beneficiários para } \\
\text { concessão do programa tarifa social. }\end{array}$ & $\begin{array}{l}\text { Política Nacional de } \\
\text { Assistência Técnica e } \\
\text { Extensão Rural na } \\
\text { agricultura familiar e } \\
\text { reforma agrária. }\end{array}$ \\
\hline 2011 & 13.300 .000 & $\begin{array}{l}\text { Programa Água para Todos, Programa } \\
\text { Rede Cegonha, Criação de variáveis } \\
\text { no PBF denominados Benefício } \\
\text { variável gestante - BVG e Beneficio } \\
\text { Variável Nutriz - BVN, PRONATEC, } \\
\text { Expansão do Programa Mulheres Mil } \\
\text { para todos os Estados. }\end{array}$ & $\begin{array}{l}\text { Início do Plano Brasil sem } \\
\text { Miséria. }\end{array}$ \\
\hline 2012 & 13.900 .000 & $\begin{array}{l}\text { Programa Telefone Social, Ação Brasil } \\
\text { carinhoso com variável paga através } \\
\text { do PBF. }\end{array}$ & \\
\hline 2013 & 13.800 .000 & $\begin{array}{l}\text { Fim da Pobreza extrema entre os } \\
\text { beneficiários do PBF segundo a PNUD, } \\
2013 \text {. }\end{array}$ & \\
\hline
\end{tabular}

Fonte: MDSA/setembro, 2016 (Elaboração própria com base nos dados do MDSA). 
Diante desse quadro, fica evidente que o PBF conta com a participação de vários programas correlatos que viabilizaram a melhoria na qualidade de vida das famílias usuárias em varias dimensões, com especial para as áreas de educação, saúde, segurança alimentar, habitação, transporte escolar, entre outros.

A esse programa incidem várias críticas que questionam sua eficácia, e para isso atribuem termos pejorativos como "bolsa esmola" ou que é um programa de cunho "assistencialista", que serve apenas como moeda de troca com fins eleitoreiros. Além disso, ainda pesa sobre os usuários o estigma de que o PBF estimula a "preguiça" e o "ócio", tornado as pessoas dependentes dele e sem "força de vontade" para procurar emprego, denotando uma visão moralista da pobreza e dos pobres (ARROYO, 2014).

Todavia, sabe-se que o programa é de caráter assistencial, que atua na perspectiva do direito e reconhece o usuário como sujeito de direitos. Além disso, O PBF promove ações diversas como o estímulo ao nível de escolarização, a qualificação profissional por meio do Programa Nacional de Acesso ao Ensino Técnico e Emprego - PRONATEC, a regularização de pequenos empreendimentos, ao microcrédito, entre outras ações que podem ser visualizadas no quadro anterior. Portanto, essas críticas não condizem com a realidade.

Em uma sociedade na qual "os $10 \%$ mais ricos da população são donos de $46 \%$ do total da renda nacional, enquanto que os $50 \%$ mais pobres - 87 milhões - ficam com apenas $13,3 \%$ do total da renda nacional" (WEISSHENIMER, 2006, p. 9), é fato que a população em situação de pobreza e extrema pobreza necessitavam de uma intervenção urgente, e, portanto, o PBF é essencial para combater os efeitos da pobreza e extrema pobreza.

Desse modo, observa-se que um programa como esse não é apenas importante, mas também necessário. Inclusive, as famílias usuárias passam por avaliações temporárias, uma vez que precisa atualizar as informações a cada dois anos, denotando a sua não perenidade. Para melhor visualizar a amplitude e a progressão do programa observe o gráfico a seguir. 
Gráfico 1 - Famílias usuárias do Programa Bolsa Família no período de 2003 a 2013.

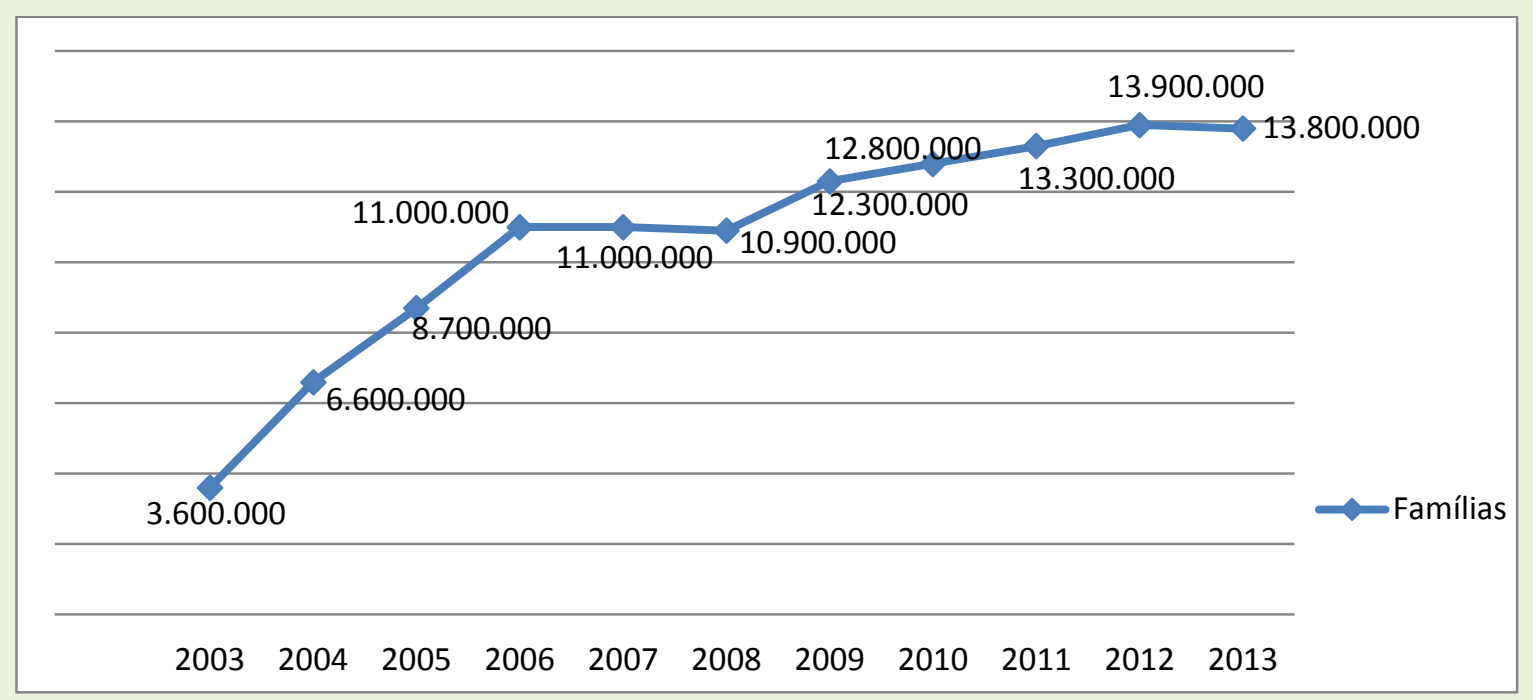

Fonte: MDSA/setembro, 2016. (Elaboração própria com base nos dados do MDSA).

O gráfico nos leva a refletir sobre os impactos que esse programa tem causado nas vidas das populações em situação de pobreza e extrema pobreza neste país. Segundo as autoras (MACHADO; GOLVEIA, 2014, p. 2):

O Bolsa Família ajudou a retirar 36 milhões de pessoas da situação de pobreza. A pobreza e a extrema pobreza somadas caíram de $23,9 \%$ para $9,6 \%$ da população. Houve uma redução inédita da redução da desigualdade de renda no Brasil nos últimos 10 anos, e o Bolsa Família foi responsável por 13\% dessa redução.

Desse modo, o PBF se revela como um importante instrumento não só de viabilização de direitos, conforme determina a Declaração Universal dos Direitos Humanos ${ }^{51}$ de 1948. Mas também favorece o controle e fiscalização social dos serviços que estão sendo prestados aos cidadãos.

É importante salientar que o PBF incide em populações distribuídas por todas as regiões do Brasil. Dentre elas, o Norte e o Nordeste são as que apresentam os maiores índices de pobreza e desigualdade social e, portanto, tendem a apresentar os maiores números em relação a famílias usuárias do PBF. Segundo o estudo intitulado "Presença do Estado no Brasil:

51 Para maiores informações consulte a Declaração Universal dos Direitos Humanos. Disponível em: <http://www.dudh.org.br/wp-content/uploads/2014/12/dudh.pdf>. 
Federação, suas Unidades e Municipalidades", realizado e divulgado pelo Instituto de Pesquisa Econômica Aplicada - IPEA em 2011, informa que "a Região Nordeste recebeu $51,1 \%$ dos benefícios do Bolsa Família distribuídos pelo governo federal em dezembro de 2011 ". Todavia, o presidente do IPEA, naquele período, Marcio Pochmann, afirma que "O Nordeste recebe mais da metade dos benefícios do Bolsa Família, mas a região possui apenas $28 \%$ da população total" do país.

O Estado do Rio Grande do Norte se localiza na região Nordeste do Brasil, tendo sua composição territorial formada por 176 munícipios, dos quais o município de Senador Elói de Souza é membro. Essa região brasileira é historicamente marcada pelas situações de pobreza e desigualdade sociais vivenciadas por sua população em função do baixo desenvolvimento52 educacional, econômico, industrial, além dos fatores climáticos, a exemplo as secas.

Considerando que o objeto deste estudo é a condicionalidade de frequência escolar, estabelecida pelo PBF, e suas contribuições para a permanência dos estudantes do ensino fundamental e usuários do programa, tem como realidade empírica o munícipio de Senador Elói de Souza, cujos dados serão apresentados a seguir.

\section{O PROGRAMA bOLSA FAMÍLIA NO MUNICíPIO DE SENADOR ELÓI DE SOUZA/RN}

O município de senador Elói de Souza está localizado na região denominada Agreste Potiguar que fica há $73,3 \mathrm{~km}$ da capital do Estado Natal. Sua extensão territorial, atualmente, é de 167,605 km distribuídos entre a zona rural e urbana, cuja origem, enquanto povoado, se deu no início do

\footnotetext{
52 O Brasil possui um Índice de Desenvolvimento Humano de 0,699, ocupando o $73^{\circ}$ lugar no ranking mundial. O Rio Grande do Norte, segundo o IBGE 2010, apresentou um IDH de 0,738 ocupando $21^{\circ}$ vaga no ranking nacional acompanhado por vários Estados das regiões Norte e Nordeste brasileiro, e por fim o município de Senador Elói de Souza, nesse mesmo período, apresentou um IDH de 0,583 ficando entre os 70 municípios da federação com índice na categoria baixo.
} 
século XIX tornando se administrativamente autônomo, através da Lei no 2.355, em 31 de dezembro de 1958.

Seu contingente populacional, segundo pesquisa realizada em 2010 pelo Instituto Nacional de Geografia e Estatística - IBGE53, era de 5.637 habitantes, dos quais 1.584 encontrava- se em situação de extrema pobreza, ou seja, com renda domiciliar per capita abaixo de $R \$ 70,00$. Isso significa que $28,1 \%$ da população municipal viviam nessa situação. A estimativa de habitantes apontadas pelo IBGE para o ano de 2016 é de 6.138 habitantes.

Consequentemente, boa parte da população municipal apresenta os critérios de elegibilidade exigidos pelo PBF para ser beneficiários. De acordo com informações do Ministério do Desenvolvimento Social e Agrário, o número de famílias cadastradas na base de dados do Cadastro Único54 para esse município até junho de 2016 era de 1.615 (mil seiscentos e quinze) famílias.

Do total apresentado, 1.150 (mil cento e cinquenta) famílias informaram renda familiar de $R \$ 0$ até $R \$ 85.00$ (oitenta e cinco reais) correspondentes à classificação de extrema pobreza. As famílias com classificação relativa à pobreza são 119 , ou seja, informaram renda de $R \$$ 85,00 (oitenta e cinco reais e um centavo) até 170,00 (cento e setenta reais) e por fim foram registradas 210 famílias que afirmaram ter renda de $R \$ 170,01$ (cento e setenta reais e um centavo), até 1/2 meio salário mínimo.

Nesse sentido, é importante destacar que dessas 1.615 famílias cadastradas, 1.117 (mil cento e dezessete) estão recebendo a quantia média de $R \$ 217,63$ (duzentos e dezessete reais e sessenta e três centavos) provenientes do benefício básico e suas variáveis (jovem, nutriz e gestante).

\footnotetext{
53 Para mais informações, consultar 0 site: $<$ http://cidades.ibge.gov.br/xtras/perfil.php?lang=\&codmun=241310\&search=rio-grande-donorte / senador-eloi-de-souza $>$.

54 O cadastro Único é operacionalizado em âmbito municipal, e as informações cadastradas migram para a base nacional. Ele representa um importante instrumento para gestão dos programas sociais, em especial o Programa de Transferência Condicionada de Renda mais conhecido como Bolsa Família.
} 
Para esse quantitativo de famílias usuárias do PBF, o Governo Federal destinou, em setembro de 2016, o valor corresponde a $R \$ 243.095,00$ (duzentos e quarenta e três mil e noventa e cinco reais), apenas para 0 município em estudo.

O município também enfrenta $\bigcirc$ problema da falta de abastecimento de água em função da estiagem prolongada. Estiagem essa que representa mais um agravante na busca por melhores condições de vida da população usuária do PBF. Em função disso, o município é assistido pelo Programa Água para Todos55, instituído através do Decreto $n^{\circ} 7.535$ de 26 de julho de 2011, cuja excursão se da por meio de parceria estabelecida entre os governos Estadual e Municipal. Na realidade do Rio Grande do Norte, esse o Programa Água para Todos é coordenado e executado pelo Exército através da operação Carro Pipa, que é responsável pela distribuição de água potável para os municípios atingidos pela estiagem.

Em relação à população com perfil de extrema pobreza, O IBGE (2010) informou que eram de $1.317(83,1 \%)$, cuja localização se dá na área rural. Já a população com esse mesmo perfil observado no meio urbano representa apenas (16,9\%), ou seja, 267 famílias.

Em relação à educação, o senso revelou que 321 pessoas com mais de 15 anos vivenciam uma situação de extrema pobreza, são analfabetos, ou seja, não sabiam ler ou escrever. Dentre eles, 152 eram chefes de domicílio. Sem mencionar o quantitativo de pobres existentes naquela realidade (IBGE, 2010). Aqui enfatiza-se apenas os "extremamente pobres" conforme nomenclatura utilizada pelo IBGE.

Com base nessas informações, pode-se observar que, nessa realidade, a população que vive no meio rural enfrenta maiores dificuldade justamente por acessarem, precariamente, direitos sociais, sobretudo, na

55 O Programa Água para Todos é uma estratégia do Plano Brasil Sem Miséria. Esse programa busca democratizar o acesso à água em áreas rurais do Brasil, e o público-alvo, as famílias usuárias do Programa Bolsa Família que vivem nesses territórios. Disponível em: $<$ http://www.mi.gov.br/documents/10157/7552bcf2-8a6f-41f3-bd85-ff6d09f31adb>. Acesso em: out. 2016. 
área educacional. Esse dado é preocupante uma vez que a pobreza é um fator real e de difícil superação.

Convém pontuar que a pobreza leva à falta de instrução, uma vez que as crianças são obrigadas a deixar a escola para trabalhar e ajudar a família, enquanto a falta de instrução perpetua a pobreza, pois, sem instrução e qualificação, não há como entrar no mundo do trabalho e sair dessa condição. A exclusão econômica resulta, por sua vez, em exclusão social e política, visto que os pobres passam a viver à margem da sociedade, com pouca capacidade de se organizarem para fazer com que suas vozes sejam ouvidas (REGO; PINSANI, 2015, p. 7).

Nesse sentido, os autores descrevem a realidade vivenciada por parte dos munícipes de Senador Elói de Souza, revelando que a falta de recursos financeiros leva a diversas violações de direitos que acabam se perpetuando por gerações. Logo, a pobreza é aqui entendida no seu sentido mais amplo, ou seja, como "privação de capabilities básicas em vez de meramente como baixo nível de renda, que é o critério tradicional de identificação da pobreza", conforme defende Amartya Sem (apud REGO; PINZANI, 2014, p. 155).

Portanto, para romper com o ciclo intergeracional da pobreza, é preciso contar com a educação formal, uma vez que ela representa um importante instrumento não só de transmissão de conhecimento, mas também de fortalecimento da cidadania e desenvolvimento de capacidades e habilidades desses estudantes. Logo, a condicionalidade referente à frequência escolar, estabelecida pelo PBF, serve como instrumento de elevação da escolarização das populações empobrecidas ampliando o seu capital cultural56 e assim aumentando as possibilidades de romper com esse ciclo intergeracional da pobreza. Afinal, o ser social é detentor de vários capitais, todos legados dos seus grupos originários, e, portanto, a escola representa apenas uma parte desses capitais (BOURDIEU, 2007).

56 Sobre Capital Cultural, Pierre Bourdieu considera o conjunto de conhecimentos adquiridos por um indivíduo ao longo da sua vida, por meio da família e da sociedade em que está inserido. Com essa teoria ele explica as desigualdades no desempenho escolar de indivíduos oriundos de grupos sociais diferentes. 
Todavia, apenas a educação formal não garante que esse ciclo seja rompido. Para que isso seja possível, é importante contar com uma infraestrutura escolar adequada, munida de profissionais qualificados e comprometidos, com currículos atualizados e flexíveis, que respeite as particularidades e singularidades apresentadas pelos estudantes em cada território. E ainda articuladas com as variáveis estruturais, produtivas e financeiras.

\section{A REALIDADE EDUCACIONAL DO MUNICÍPIO DE ELÓI DE SOUZA}

A Política de educação brasileira é norteada pela Lei $n^{\circ} 9.394$, de 20 de dezembro de 1996 que determina as Diretrizes e Bases da Educação LDB, é planejada e executada entre seus entes federados conforme determina o artigo Art. 8०: "A União, os Estados, o Distrito Federal e os Municípios organizarão, em regime de colaboração, os respectivos sistemas de ensino".

Considerando a Política nacional de educação, ao município compete ofertar educação básica nos níveis elementar, ou seja, educação infantil - destinadas a crianças de 04 e 05 anos (executados nas creches e pré-escolas) e o nível fundamental destinado a crianças e adolescente de 06 a 17 anos.

Essa diretriz, idade e série, é uma meta que a política educacional estabelece com objetivo de desenvolver as habilidades e capacidades dos estudantes respeitando os seus respectivos estágios de desenvolvimento biológico e intelectual.

No município de Senador Elói de Souza, a educação infantil é composta por 04 centros infantis que se localizam um na zona urbana e três na zona rural57. Essas escolas funcionam nos turnos matutino e vespertino.

57 Os centros infantis estão localizados na zona rural do município, especificamente nas seguintes comunidades: Lagoa dos Cavalos, Lagoa dos Novilhos e Assentamento Passagem do Juazeiro, respectivamente. 
Todavia, dois centros infantis situados na zona rural estão em fase de implantação da educação em tempo integral.

Quanto ao ensino fundamental, o município dispõe de duas Escolas. Sendo elas a Escola Municipal Professor Francisco Ernesto - EMPROFEC, localizada na Zona Urbana e a Escola Municipal Euclides Lins situada na zona rural. Ambas apresentando índice de desempenho58 crescente, segundo dados fornecidos pelo Instituto Nacional de Pesquisas Educacionais Anísio Teixeira - INEP.

Analisando a prestação de serviços educacionais relativos à educação infantil ao ensino médio, presente no território municipal, vale ressaltar que todo esse serviço é formado, exclusivamente, pelas instituições públicas de ensino, seja em âmbito Municipal ou Estadual59.

A educação de nível superior está presente no município através de convênio firmado com a faculdade privada IBRAPES-UVA, tornando-se polo presencial do curso de Pedagogia daquela instituição de ensino. Não obstante, para aqueles que fazem outros cursos, geralmente na capital Natal/RN, o município é responsável pelo transporte desses estudantes, cujo deslocamento se dá por meio de veículo próprio.

Essas informações revelam que existe, de fato, no município, uma gestão comprometida com a educação da sua população em todos os níveis. Considerando os níveis que é de competência do município, correspondentes à educação infantil ao ensino fundamental, esse esforço é aferido pelo INEP por meio das suas avaliações contínuas como pode ser observado no quadro a seguir:

58 O Índice de Desenvolvimento da Educação Básica (IDEB) foi criado pelo Instituto Nacional de Estudos e Pesquisa Educacionais Anísio Teixeira - INEP em 2007 utilizando em um só indicador dois conceitos igualmente importantes para a qualidade da educação: fluxo escolar e médias de desempenho nas avaliações.

59 Em âmbito Estadual, o município conta com uma Escola Estadual Desembargador Vicente lemos, situada na zona urbana, e oferta educação referente ao ensino médio. 
Quadro 2 - Média IDEB e meta estabelecida para o município de Elói de Souza/RN correspondente ao $5^{\circ}$ e $6^{\circ}$ anos do ensino fundamental, por ano.

\begin{tabular}{|l|c|c|c|c|c|c|}
\hline MÉDIA IDEB & 2005 & 2007 & 2009 & 2011 & 2013 & 2015 \\
\hline BRASIL & 3.8 & 4.2 & 4.6 & 5.0 & 5.2 & 5.5 \\
\hline RIO GRANDE DO NORTE & 2.7 & 3.4 & 3.9 & 4.1 & 4.4 & 4.8 \\
\hline ELÓI DE SOUZA/RN & 2.5 & 3.0 & 2.8 & 3.2 & 3.2 & 3.0 \\
\hline $\begin{array}{l}\text { META ESTABELECIDA PARA O } \\
\text { MUNICÍPIO }\end{array}$ & - & 2.9 & 2.9 & 3.3 & 3.6 & 3.9 \\
\hline
\end{tabular}

Fonte: INEP, 2016.

Diante do quadro apresentado observa-se que houve avanços, sobretudo entre os anos 2007 a 2011. Os dados revelam que a meta estabelecida para o ano de 2007 foi superada. Todavia, em 2009, apresentou um declínio em dois pontos percentuais. Mas continua em constante crescimento, chegando bem próximo à meta estabelecida para 2011.

A partir de 2013 até 2015, o índice manteve-se entre 30 e 32 pontos percentuais, não sendo suficiente para atingir a meta estabelecida para esse período. Todavia, cabe destacar que esse nível de ensino está aquém se comparados à média nacional. Mas se aproxima da média apresentada no Estado do Rio Grande do Norte.

Quadro 3 - Média IDEB e meta estabelecida para o município de Elói de Souza/RN correspondente ao $8^{\circ}$ e $9^{\circ}$ anos do ensino fundamental, por ano.

\begin{tabular}{|l|c|c|c|c|c|c|}
\hline MÉDIA IDEB & 2005 & 2007 & 2009 & 2011 & 2013 & 2015 \\
\hline BRASIL & 3.5 & 3.8 & 4.0 & 4.1 & 4.2 & 4.5 \\
\hline RIO GRANDE DO NORTE & 2.8 & 3.1 & 3.3 & 3.4 & 3.6 & 3.8 \\
\hline ELÓI DE SOUZA/RN & 2.3 & 2.4 & 2.6 & 2.3 & 2.8 & 3.4 \\
\hline $\begin{array}{l}\text { META ESTABELECIDA PARA O } \\
\text { MUNICÍPIO }\end{array}$ & - & 2.4 & 2.5 & 2.8 & 3.1 & 3.5 \\
\hline
\end{tabular}

Fonte: INEP, 2016.

Conforme os dados apresentados, os estudantes oriundos do $8^{\circ}$ e $9^{\circ}$ ano apresentam um desempenho em constante crescimento, mantendo uma aproximação significativa com as metas estabelecidas. Inclusive 
chegando a cumprir a meta dos anos 2007 e superando a de 2009, e se aproximando da meta estabelecida para 2015.

Em 2015 o munícipio apresentou uma média de 3.4 pontos, cuja meta estabelecida era de 3.5 pontos. Revelando uma crescente elevação no desempenho dos estudantes segundo pesquisa realizada pelo INEP. Observa-se que houve avanços significativos na medida em que a educação vem recebendo incentivos para continuar sendo desenvolvida da melhor forma possível. Além disso, essa realidade não está muito distante da média apresentada em âmbito estadual.

Numa realidade em que $28,1 \%$ (IBGE, 2010) da sua população viviam em situação de extrema pobreza, manter-se na escola é um desafio constante. Nesse sentido, o Programa Bolsa Família passa a contribuir no processo de acesso e permanência dos filhos pertencentes a famílias socioeconomicamente vulneráveis.

Esse dado é importante e cabe reflexão em vários sentidos. Se considerarmos que o contingente estudantil, relativo ao ensino fundamental presente no munícipio de Senador Elói de Souza, em 2016, é de 965 estudantes. Sendo 638 matriculados na EMPROFEC - Zona Urbana e 327 matriculados EMEL na Zona rural. Desse universo são beneficiários do Programa Bolsa Família 491 estudantes da EMPROFEC, 286 estudantes da EMEL. Portanto, eles precisam manter uma frequência média entre $75 \%$ e 85\% para que não haja nenhum tipo de penalidade por parte do PBF. Consequentemente, espera-se que passando mais tempo no ambiente escolar esse estudante possa acessar outros conhecimentos que irão contribuir não só para ampliar sua visão de mundo, mas também possibilitar o ingressar no mundo do trabalho com melhores remunerações.

Essa é uma expectativa que necessita do empenho de outros sujeitos sociais em especial a comunidade escolar para que possa transformar aquele ambiente em um local acolhedor que trabalhe as questões relativas à situação de pobreza trazida por seus estudantes sem fazer distinção entre os usuários e não usuários do PBF. 
Logo, essa expectava se revela como um desafio a ser superado, tanto para os gestores educacionais quanto para as famílias usuárias do programa. Sobretudo, para aquelas oriundas da Zona Rural, cujos filhos estão matriculados na Escola Municipal Euclides Lins, uma vez que os maiores índices de vulnerabilidade social estão presentes naquela realidade.

\section{A ESCOLA MUNICIPAL EUCLIDES LINS - EMEL: uma realidade a ser desvelada}

A comunidade Lagoa dos Cavalos compõe uma das localidades pertencente à zona rural do Município de Senador Elói de Souza/RN. Sua população vivencia uma situação de desvantagem social em relação à zona urbana. Inclusive apresentando o maior índice de famílias usuárias do PBF como foi visto anteriormente.

Logo, a pobreza e desigualdade social são predominantes naquela região. Para superar essa condição, que é intergeracional, é preciso reconhecer a educação como meio para ascender socialmente, sobretudo quando essa educação é pautada em princípios críticos, éticos e políticos que respeitem o saber que cada indivíduo carrega consigo, e assim promova sua autonomia enquanto sujeito de direitos, como destaca os estudos de Freire (2006).

Essa mobilidade social representa um dos objetivos do PBF, no momento em que condiciona a frequência escolar ao recebimento do valor repassado pelo programa. Consequentemente, as crianças e adolescente terão acesso a oportunidades que seus pais ou responsáveis não tiveram e, assim, tendo condições de superar a realidade socioeconômica vivenciada pelos munícipes de Senador Elói de Souza.

A Escola Municipal Euclides Lins foi fundada em 1976 na comunidade Lagoa dos Cavalos - Zona Rural. Nesse período eram ministradas apenas as séries iniciais (antigo primário). Com o avanço dos processos democráticos e o reconhecimento da educação como direito social e o incentivos do governo federal, a escola foi sendo ampliada paulatinamente. 
Consequentemente, o número de alunos matriculados aumentou significativamente, sobretudo no período entre 2004 a 2016, como pode ser observado no gráfico a seguir:

Gráfico 2 - Progressão de Matriculas realizada na EMEL no período entre 2000 a 2016.

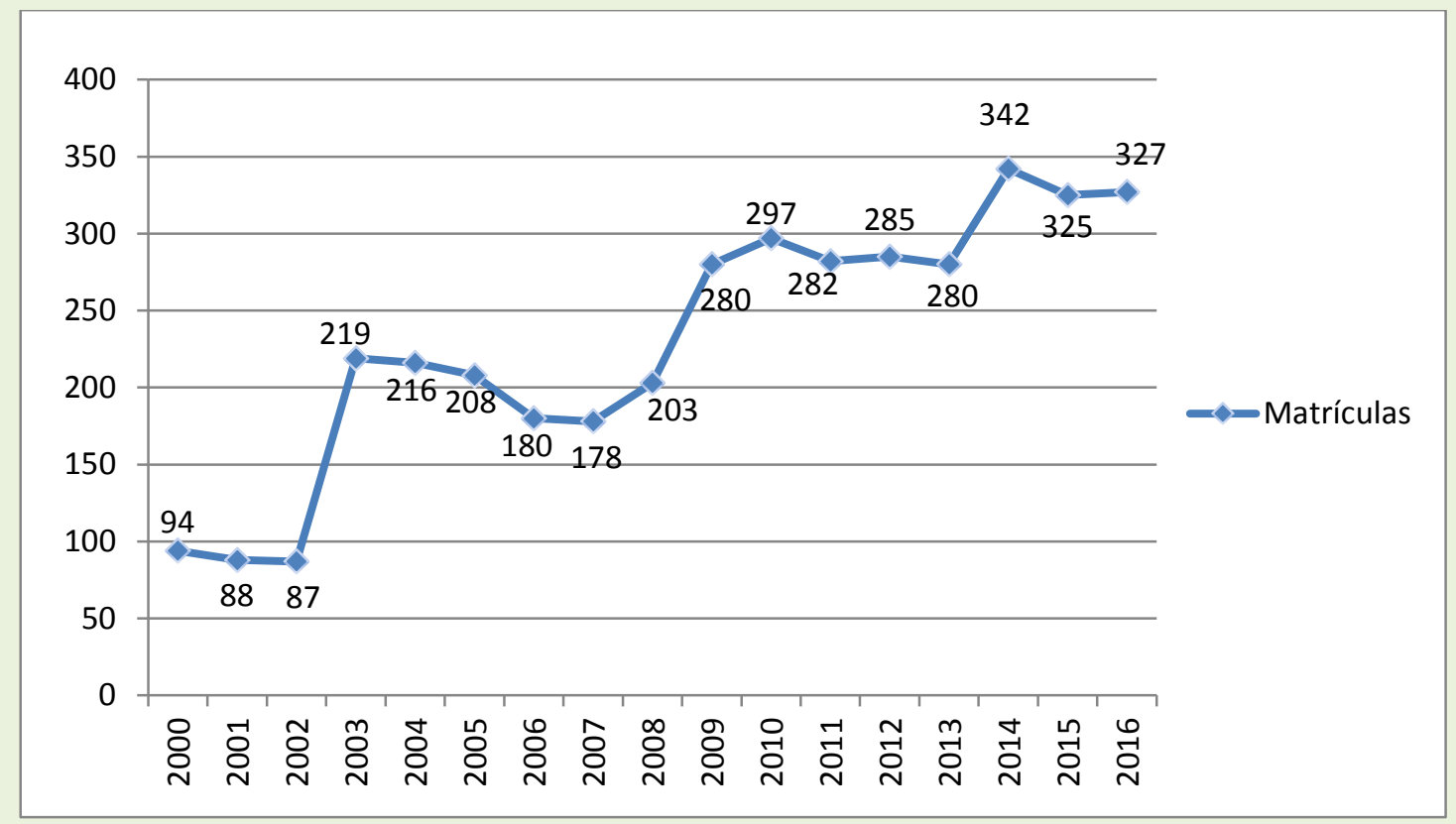

Fonte: Secretariaria Municipal de Educação de Senador Elói de Souza, 2016 (Gráfico construído pela autora).

A infraestrutura da EMEL é composta por salas de aulas com sistema de ventilação mecânica (ventiladores elétricos), quadra poliesportiva coberta, sala de estudos para os professores com banheiro integrado e acesso à internet, cozinha, refeitório, banheiros separados por gênero, com adaptação para pessoas com deficiência, minibiblioteca, equipamento audiovisual, e futuramente, um laboratório de informática. O corpo docente é composto por 23 professores efetivos.

Atualmente, a escola atende a 327 estudantes do ensino fundamental, distribuídos em dois turnos: matutino destinado aos estudantes das séries iniciais ( $1^{\circ}$ ao $5^{\circ}$ ano) e vespertino destinado aos estudantes das séries finais ( $6^{\circ}$ ao $9^{\circ}$ ano). Desse universo, 286 estudantes são beneficiários com o PBF, ou seja, apenas 41 estudantes não atendem ao critério de 
elegibilidade do programa, ou excede o quantitativo de filhos beneficiados. Cabe lembrar que os quantitativos máximos de filhos beneficiados pelo programa são de no máximo cinco.

Em outras palavras, a pesquisa revelou que em 2016 o total de estudantes usuários do PBF é de $87,5 \%$. Porém, nos últimos três anos esses percentuais vêm sofrendo alterações como pode ser observado na tabela a seguir:

Quadro 4 - Quantitativo de estudantes matriculados na EMEL e beneficiários do Programa Bolsa Família no período de 2014 a 2016.

\begin{tabular}{|c|c|c|c|c|}
\hline \multirow{2}{*}{ Período } & Total de & \multicolumn{3}{|c|}{ Beneficiários do Programa Bolsa Família } \\
\cline { 3 - 5 } & Matrículas & $75 \%$ Frequência & $85 \%$ Frequência & Total \\
\hline 2014 & 342 & 20 estudantes & 263 estudantes & $83 \%$ \\
\hline 2015 & 325 & 27 estudantes & 225 estudantes & $77,5 \%$ \\
\hline 2016 & 327 & 15 estudantes & 271 estudantes & $87,5 \%$ \\
\hline
\end{tabular}

Fonte: Secretaria Municipal de Educação de Senador Elói de Souza, 2016.

A Tabela 3 revela que, nos últimos três anos, o número de matrículas se aproxima da quantidade de estudantes usuários do PBF, demonstrando a fragilidade socioeconômica das famílias residentes naquela localidade. Consequentemente, pode-se inferir que o PBF vem contribuindo no processo de permanência desses estudantes na instituição de ensino. Porém, é importante saber até que ponto essa frequência reflete no desempenho do estudante. Para tanto, o indicador quantitativo utilizado foi o número de estudantes evadidos 60 ao longo desses dezesseis anos, com ênfase nos últimos três anos, como podemos ver a seguir:

60 Cabe salientar que a utilização de indicadores quantitativos relativos a matrículas e evasão escolar não refletem o desempenho qualitativo do estudante, uma vez que não analisa as situações que levou esse estudante a evadir-se do contexto escolar. Mas servem como indicadores para investigações futuras. 
Gráfico 2 - progressão de matrículas e taxa de evasão observada na EMEL no período de 2000 a 2016.

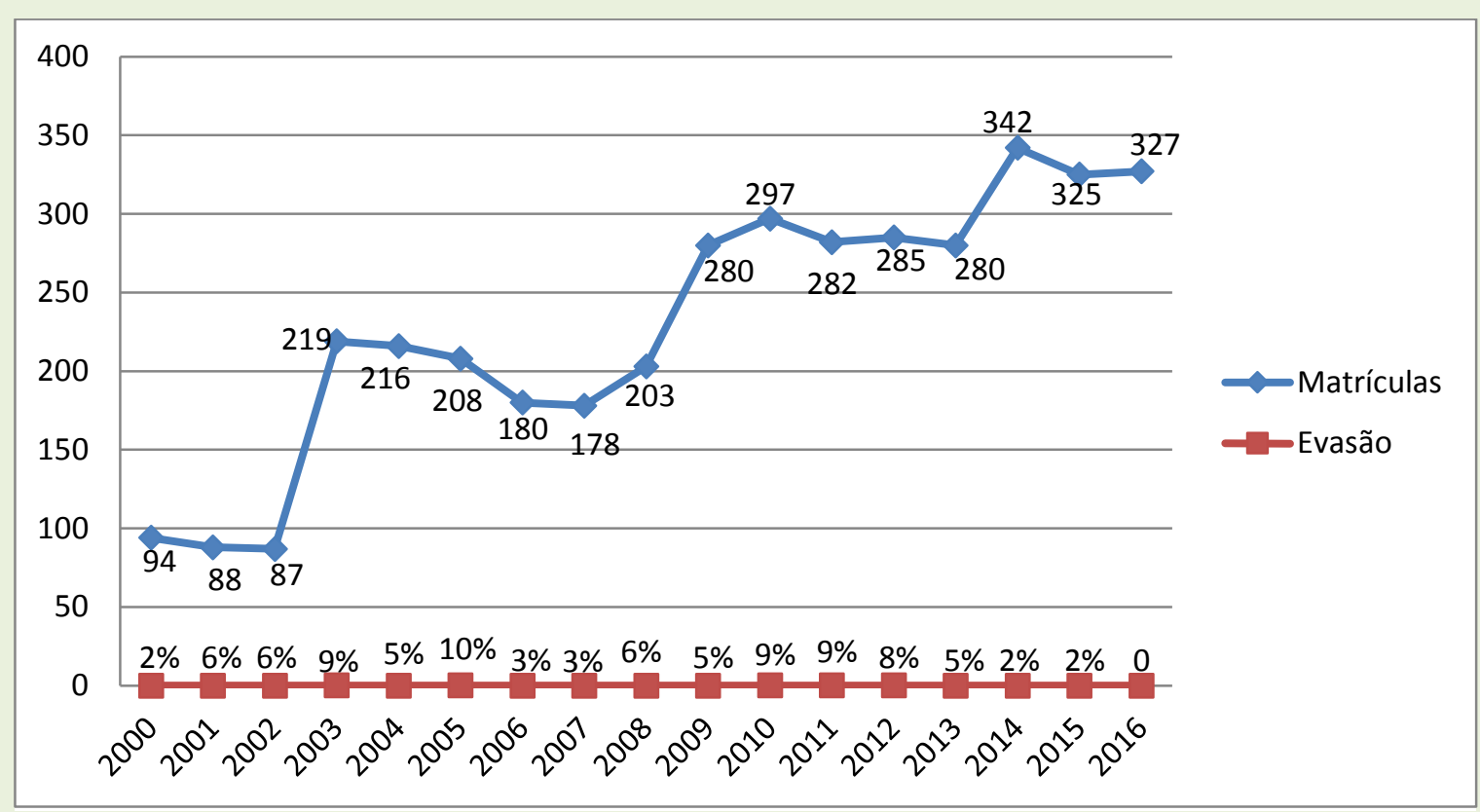

Fonte: Secretariaria Municipal de Educação de Senador Elói de Souza, 2016 (Gráfico construído pela autora).

O gráfico revela que o percentual de evasão correspondente a dezesseis anos de atuação da EMEL é baixo se considerar com a média nacional que é $24,3 \%$, segundo dados da PNUD (2012).

Considerando que o estudo enfoca a questão da condicionalidade do PBF relativo à frequência escolar, é notório que as maiores taxas de evasão se encontram no ano de 2005 (10\%), um ano depois da implementação do PBF.

Entre os anos 2010 (8\%), 2011 (9\%) e 2012 (9\%), o índice de evasão inicia o processo de leve declínio, apresentando uma queda significativas em 2014 e 2015, apresentando os percentuais de 2 e 3\%, respectivamente. Os dados relativos a 2016 são iguais a zero, uma vez que a pesquisa foi realizada antes de encerrar o referido ano letivo6l.

\footnotetext{
${ }^{61}$ Para mais detalhamentos sobre os índices de matrícula, repetência e evasão, da escola EMEL, veja tabela em anexo.
} 
Analisando os dados relativos, o rendimento dos estudantes do ensino fundamental II, correspondentes às turmas do sexto ao nono ano (B) 62 , no período entre 2014 a 2015, observa-se que no ano de 2014 a escola Euclides Lins contava com sete turmas do ensino fundamental II, todas no turno vespertino, distribuídas da seguinte forma: duas turmas de sexto ano ( $A$ e $B$ ), duas turmas de sétimo ano ( $A$ e $B$ ), duas turmas de oitavo ( $A$ e B ) ano e uma turma de nono ano, perfazendo um total de 93 estudantes.

Em 2015 as turmas do ensino fundamental II contavam com duas turmas de sexto ano ( $A$ e $B$ ), uma turma de sétimo ano (A), duas turmas de oitavo ano ( $A$ e B) e uma turma de nono ano (A) perfazendo um total de 95 estudantes.

Quadro 5 - Desempenho dos estudantes das turmas do ensino fundamental II correspondentes aos $6^{\circ}$ e $9^{\circ}$ ano da Escola Municipal Euclides Lins no ano de 2014.

\begin{tabular}{|c|c|c|c|c|c|c|}
\hline Ano & Turma & $\begin{array}{c}\text { Quantidade } \\
\text { de } \\
\text { Estudantes }\end{array}$ & $\begin{array}{c}\text { Frequência } \\
\text { Media }\end{array}$ & Aprovado & $\begin{array}{c}\text { Não } \\
\text { Aprovados }\end{array}$ & Evadido \\
\hline 2014 & $6^{\circ}$ ano B & 30 & $98 \%$ & 12 & 18 & 0 \\
\hline 2014 & $7^{\circ}$ ano B & 23 & $97 \%$ & 11 & 11 & 1 \\
\hline 2014 & $8^{\circ}$ ano B & 18 & $98 \%$ & 13 & 3 & 1 \\
\hline 2014 & $9^{\circ}$ ano A & 22 & $98 \%$ & 19 & 1 & 1 \\
\hline
\end{tabular}

Fonte: Atas de resultados finais da Escola Municipal Euclides Lins, 2014.

Diante dos dados apresentados, observa-se que em 2014 os estudantes apresentaram uma taxa média de frequência satisfatória, atendendo a condicionalidade do PBF referente à frequência escolar correspondente a $85 \%$ destinados a estudantes até 15 anos e $75 \%$ para estudantes com idade entre 16 e 17 anos.

Os índices de evasão e transferência são ínfimos. Porém, o desempenho apresentado nos $6^{\circ}$ e $7^{\circ}$ anos é preocupante, pois revelam

\footnotetext{
62 As turmas denominadas B foram escolhidas para análise, segundo orientação do gestor escolar, por conter um numero significativo de estudantes com dificuldades educacionais, ou seja, repetentes. Em turmas únicas serão analisados dados da turma A.
} 
uma taxa média de $50 \%$ de estudante que não avançou para as séries seguintes.

Em relação aos estudantes da mesma série no ano de 2015, serão apresentados os dados a seguir:

Quadro 6 - Desempenho dos estudantes das turmas do ensino fundamental II correspondentes aos $6^{\circ}$ e $9^{\circ}$ ano da Escola Municipal Euclides Lins no ano de 2015.

\begin{tabular}{|c|c|c|c|c|c|c|c|}
\hline Ano & Turma & $\begin{array}{c}\text { Quantidade } \\
\text { de } \\
\text { Estudantes }\end{array}$ & $\begin{array}{c}\text { Frequência } \\
\text { Media }\end{array}$ & Aprovado & $\begin{array}{c}\text { Não } \\
\text { Aprovados }\end{array}$ & Evadido & $\begin{array}{c}\text { Transferi } \\
\text { do }\end{array}$ \\
\hline 2015 & $6^{\circ}$ ano B & 25 & $98 \%$ & 17 & 8 & 0 & 0 \\
\hline 2015 & $7^{\circ}$ ano B & 19 & $95 \%$ & 17 & 2 & 0 & 0 \\
\hline 2015 & $8^{\circ}$ ano A & 32 & $97 \%$ & 19 & 10 & 1 & 2 \\
\hline 2015 & $9^{\circ}$ ano A & 19 & $97 \%$ & 19 & 0 & 0 & 0 \\
\hline
\end{tabular}

Fonte: Atas de resultados finais da Escola Municipal Euclides Lins, 2015.

Os dados revelam que a assiduidade apresentada pelos estudantes usuários do PBF é satisfatória. Inclusive, houve um aumento nas taxas de aprovação relativas a todas as séries se comparadas a 2014. Esse dado revela que houve um avanço significativo, e a meta, segundo o gestor, é sempre melhorar esses índices. Afinal, estamos anualizando as turmas que apresentam as maiores dificuldades para aprovação.

Merece, nesse contexto, pontuar que o programa Bolsa Família assiste a maioria desses estudantes, de 2014 e 2015, e aproximadamente $98 \%$ deles atenderam a condicionalidade estabelecida pelo programa. Todavia, a participação das famílias no contexto escolar ainda é insuficiente. Sobretudo os responsáveis pelos estudantes com maiores índices de indisciplina. $O$ gestor destaca que "os responsáveis daqueles que mais dão trabalho só aparecem na escola para pegar a declaração de frequência quando o beneficio é bloqueado".

Diante disso, evidencia-se que o viés financeiro do programa se revela como sendo "a principal" motivação dos pais e/ou responsáveis para incentivar os estudantes a permanecer na escola. Todavia, é preciso considerar o contexto social que está sendo estudado. Considerando que se 
trata de uma comunidade socioeconomicamente fragilizada, as questões objetivas, como alimentar-se, acaba por se sobressair diante de tantas necessidades apresentadas pelas famílias. Nesse sentido, é compreensível que esses responsáveis apresentem um "certo medo" diante da possibilidade de perder a remuneração oriunda do programa.

Quanto à questão da alta taxa de assiduidade, a pesquisa revelou outro aspecto importante. Trata-se da inserção na educação na perspectiva do direito e, portanto, a gestão da escola não fica inerte ao identificar um estudante com baixa frequência.

A escola dispõe de uma equipe comprometida com a educação dos estudantes e está em constante vigilância. Assim, ao identificar um estudante com baixa frequência, a primeira inciativa a ser tomada é acionar os pais ou responsáveis a comparecer à escola, objetivando conhecer os motivos que levaram o estudante a faltar. Porém, nem sempre esse "chamado" é atendido a contento pelos responsáveis, sobretudo para aqueles estudantes com maiores índices de indisciplina.

Sob essas condições, a direção escolar age de outra forma, ou seja, ao perceber a baixa frequência e a ausência dos pais e/ou responsáveis em comparecer à escola. Notifica-se a situação ao Conselho Tutelar - órgão de proteção e defesa dos direitos das crianças e adolescentes - para auxiliar na elucidação das circunstancias que originou essa infrequência. Afinal, por trás de uma situação de infrequência pode estar escondida uma série de violências, a exemplo: exploração do trabalho infantil, abuso e exploração sexual, negligência de outras ordens, violência doméstica, abuso de álcool e outras drogas, entre outros.

A pesquisa revela que essas situações de infrequência estão presentes, em sua maioria, nas famílias com maiores índices de vulnerabilidade social, e usuárias do PBF. Porém, após o PBF esse fenômeno tem diminuído. Isso significa que a condicionalidade relativa à frequência escolar é cumprida com êxito pelos estudantes e seus responsáveis que os incentivam a comparecer às aulas. 
Outro aspecto importante é o baixo índice de evasão. Considerando a realidade em análise, esse índice serve como indicativo de que a condicionalidade contribui para a permanência do estudante beneficiário no contexto escolar. Embora existam algumas críticas relativa a essa forma de "cobrar" a frequência do usuário como destacam (OLIVEIRA; DUARTE, 2005, p. 294):

\begin{abstract}
Apesar de esses programas, no Brasil, estarem diretamente associados à educação, este aspecto tem sido traduzido somente na cobrança da frequência às aulas, o que pode ser eficaz no sentido de retirar as crianças das ruas, pelo menos por um período do dia, mas não altera o quadro de pobreza das futuras gerações, via educação.
\end{abstract}

Na realidade analisada, ficou evidente que as famílias usuárias do PBF estão conseguindo manter seus filhos na escola e distante do trabalho infantil. Desse modo, as chances desses estudantes ampliarem o seu conhecimento aumentam significativamente. Logo, a condicionalidade tem um aspecto pedagógico tanto para os estudantes quanto para seus pais e/ou responsáveis, que serão impulsionados a buscar meios para superação da pobreza em médio e longo prazo.

Todavia, a ampliação dos anos de ensino das famílias usuárias do PBF representa apenas uma das várias estratégias para alcançar a emancipação dos sujeitos envolvidos. Para tanto, é preciso articulação de outras políticas sociais, a exemplo: investimentos em geração de emprego e renda tendo por base as localidades de origem. Fortalecimento do sentimento de pertencimentos desses sujeitos sociais por meio do resgate cultural, articulação contínua entre os entes federados (município, estados e união), entre outros. Portanto, o PBF e suas condicionalidades precisam ser fortalecidos e melhorados continuamente.

Em relação ao ambiente estrutural da escola, foi possível observar que ela dispõe de infraestrutura adequada para o desenvolvimento de seus estudantes. Além de um corpo docente qualificado e comprometido com o desenvolvimento de todos. 
A escola Euclides Lins figura uma realidade, positiva, da educação ofertada à população presente em comunidades rurais no nordeste brasileiro. Embora existam fragilidades, é notório o esforço de todos em ofertar uma educação de qualidade sem distinção territorial entre urbano e rural. Contrariando as proposições presentes no imaginário de muitas pessoas. Entretanto, não foi observado nenhum equipamento de representação política dos estudantes, a saber: um grêmio estudantil. Uma vez que ele é equipamento de mobilização social e política que não faz parte do contexto escolar.

\section{CONSIDERAÇÕES FINAIS}

O estudo analisou o Programa Bolsa Família com ênfase na condicionalidade relativa à frequência escolar. Com a perspectiva de avaliar suas contribuições para permanência dos estudantes usuários no ambiente educacional, utilizou os dados relativos à evasão escolar desses estudantes no período de 2000 a 2016, com ênfase nos últimos dois anos.

A pesquisa revelou que essa condicionalidade contribui para permanência dos seus usuários na escola. Porém, possui algumas fragilidades, sobretudo no aspecto do desempenho educacional e a baixa participação dos pais ou responsáveis no cotidiano escolar. Consequentemente, as famílias beneficiadas parecem privilegiar os aspectos financeiros, é o que se sobressai. Em outras palavras, as questões de ordem financeiras são privilegiadas em detrimento das questões cognitivas e pedagógicas.

Portanto, do que foi exposto, verifica-se que apesar do caráter restritivo dos critérios de elegibilidade dos beneficiários do PBF (pois ao tomar como critério único de seleção a renda exclui famílias que apesar de estarem situadas em uma faixa de renda um pouco acima do valor definido e que também se encontram em situação de vulnerabilidade e pobreza não podem ser incluídas no PBF), o Programa tem o mérito de ter o efeito 
distributivo, em que a focalização das suas ações no combate à pobreza atende às necessidades emergências e básicas da população usuária.

Para o enfrentamento da pobreza, é primordial que os programas venham acompanhados de uma ativa e permanente política de geração de emprego e renda e de um ambiente macroeconômico favorável às políticas sociais. É preciso que os gestores locais se articulem para desenvolver estratégias de fomento à economia local, utilizando aspectos regionais para desenvolvimento das potencialidades do município e regiões adjacentes.

Entretanto, não resta dúvida que para as famílias beneficiadas do PBF do município de Elói de Souza, esse Programa é uma importante fonte de provisão de renda para um contingente bastante vulnerável da população, com repercussões positivas. A exemplo, a manutenção da subsistência, a movimentação da economia local, a participação da família no ambiente escolar, ainda que mínimo, mas já ouve avanços.

No tocante às condicionalidades de frequência escolar, a pesquisa revelou que o programa tem contribuído para elevar as taxas de matrículas, uma vez que a escola apresentou uma população estudantil composta por uma maioria de usuários do PBF. Todavia, cabe salientar a necessidade de integração com outros programas que apontem para a promoção de direitos e que construam as condições para sua emancipação.

\section{REFERÊNCIAS}

ARROYO, G. M. Pobreza desigualdades e educação: curso de especialização educação, pobreza e desigualdade social (lato sensu). Módulo Introdutório. Brasília: MEC, 2014.

BOURDIEU, P. Os três estados do capital cultural. In: NOGUEIRA, M. A.; CATANI, A. (Org.). Escritos de Educação, 3. ed. Petrópolis: Vozes, 2007.

BRASIL, Instituto Nacional de Estudos e Pesquisas Anísio Teixeira. Índice de Desenvolvimento da Educação Básica. Município Senador Elói de Souza/RN, 2016. Disponível em: <http://ideb.inep.gov.br/resultado/>. Acesso em: 25 set. 2016. 
BRASIL. Lei n 10.836 de 09 de janeiro de 2004. Institui o Programa Bolsa família e dá outras providências. Diário Oficial [da] República Federativa do Brasil, Brasília, 12 jan. 2004.2 Disponível em: <http://www.planalto.gov.br/ccivil_03/_ato2004-2006/2004/lei/l10.836.htm.> Acesso em: 20 ago. 2016.

BRASIL. Lei $n^{\circ}$ 9.394, de 20 de dezembro de 1996. Estabelece as Diretrizes e Bases da Educação Nacional - LDB. Diário Oficial [da] República Federativa do Brasil, Brasília, 23 dez. 1996. Disponível em: <https://www.planalto.gov.br/ccivil_03/Leis/L9394.htm.> Acesso em: 15 ago. 2016.

BRASIL, Ministério do Desenvolvimento Social e Combate à Fome. Plano Brasil sem miséria no seu município. Brasília, 2013. Disponível em: <http://aplicacoes.mds.gov.br/sagi/RIv3/dadosSv/cartilha_msm/CartilhaBSM. pdf.> Acesso em: 01 out. 2016.

BRASIL. Ministério do Desenvolvimento Social e Agrário. 10 anos de Bolsa Família: nossa vida melhorou. Disponível em: <http://bolsafamilia10anos.mds.gov.br/linhadotempo.> Acesso em: 22 set. 2016.

BRASIL, Ministério do Desenvolvimento Social e Combate à Fome. Norma Operacional Básica do Sistema Único de Assistência Social NOB/SUAS. Brasília, 2005.

INSTITUTO BRASILEIRO DE GEOGRAFIA E estatísticA (IBGE). Censo Demográfico 2010. Disponível em: <http://www.ibge.gov.br/home/estatistica/populacao/censo2010/resultados _gerais_amostra/resultados_gerais_amostra_tab_uf_microdados.shtmault.sht m>. Acesso em: 22 set. 2016.

FREIRE, P. Pedagogia da autonomia: Saberes necessários a prática educativa. 33. ed. São Paulo: Paz e Terra, 2006.

MACHADO, L. G. M.; GOLVEIA, L. Bolsa Família: 11 anos e 11 conquistas. Uma análise livre de preconceitos revela que o programa aumenta a frequência escolar e cria uma população mais saudável e uma sociedade mais igualitária. Carta Capital, publicado em 24 de outubro de 2014. Disponível em: $\quad$ http://www.cartacapital.com.br/politica/bolsa-familia-1 1-anos-e-1 1conquistas-4636.html.> Acesso em: 15 set. 2016.

OLIVEIRA, D. A.; DUARTE, A. Política educacional como política social: uma nova regulação da pobreza. Perspectiva, Florianópolis, v. 23, n. 2, p. 279-301, jul./dez. $2005 . \quad$ Disponível em: <http://www.fae.ufmg.br/gestrado/files/artigos/reguldapobreza.pdf>. Acesso em: 22 out.2016.

PNUD. Programa das Nações Unidas para o Desenvolvimento no Brasil. Site do programa das Nações Unidas para o Desenvolvimento no Brasil, 2012. 
Disponível em: <http://www.pnud.org.br/>. Acesso em: Acesso em: 15 set. 2016.

REGO, W. L.; PINZANI, A. Pobreza e Cidadania: curso de especialização educação, pobreza e desigualdade social (lato sensu). Módulo I. Brasília: MEC, 2014.

SUPLICY, E. Programa Garantia de Renda Mínima. Disponível em: <http://guerrilheirodoentardecer.blogspot.com.br/2010/01/projeto-de-rendaminima-de eduardo.html.> Acesso em: 25 set. 2016.

WEISSHEIMER, M. A. Bolsa Família: avanços, limites e possibilidades do Programa que está transformando a vida de Milhões de famílias no Brasil. São Paulo: Editora Fundação Perseu Abramo, 2006.

Recebido em: Setembro de 2016 Aceito em: Dezembro de 2016 